\title{
Audit in a diagnostic breast imaging service
}

\author{
Auditoria em serviço de diagnóstico por imagem da mama
}

\section{Hilton Koch ${ }^{1}$}

The present issue of Radiologia Brasileira includes a study discussing the undertaking of an audit in the diagnostic breast imaging service of a private institution and comparing such audit results with those recommended in the literature. The authors conclude that the complete internal audit of the mammography unit reflects the quality of the service and, as a result, contributes for the early detection and reduction of mortality related to breast cancer ${ }^{(\mathbf{1})}$.

In 1990 we decided to undertake the first audit that has been known in a radiology service, and the choice fell on the area of mammography.

At that time, the Health Ministry intended to set up a program for early breast cancer detection, providing Brazilian cities with mammography apparatuses and teaching local physicians to read and interpret mammograms.

We had the time to undertake a survey on the number of existing mammography apparatuses and on the mammograms quality. Such a survey was sponsored and carried out by Colégio Brasileiro de Radiologia (CBR) (Brazilian College of Radiology) and by Instituto de Radioproteção e Dosimetria da Comissão Nacional de Energia Nuclear (Institute of Radioprotection and Dosimetry - National Committee for Nuclear Energy). Based on the results from this first audit, we primarily sought to teach the radiologists themselves what they could do to improve the quality of the mammograms as well as their interpretation skills. For this purpose, a Commission of Mammography was created including recognized radiologists with experience in breast diagnosis and that had also to learn a lot in order to be able to teach. The resignation in relation to the work and acquired knowledge stagnation lead to relaxation in the attention to the quality of the service itself. Thus, a periodic audit of the services would be recommended. However, the arrogance because of the knowledge acquired along years brings about the felling of being immutable.

The Federal Government has donated mammography apparatuses without evaluating the targeted population and the real necessities in terms of materials (film cassettes), image processing resources, human resources (technicians and radiologists skills), and even appropriate premises and

1. Full Professor of Radiology at Universidade Federal do Rio de Janeiro (UFRJ) and Pontifícia Universidade Católica do Rio de Janeiro (PUC-Rio), Former President of Colégio Brasileiro de Radiologia. E-mail: hakoch@uol.com.br. facilities for equipment installation. If an audit was undertaken to review those mammography apparatuses donated by the Government, we might see that practically none of those apparatuses was utilized and not even a single mammogram was produced.

During many years, the CBR Commission of Mammography roamed about the whole country to aid in the improvement of the services quality. Improvements were observed in mammography apparatuses, in the quality of films, and in the diagnoses reported in more than one hundred published studies, yet an important detail was missing: to audit diagnostic results. The service has produced a determined number of mammograms. How many of such mammograms would have their quality approved? According to the CBR Commission of Mammography itself, there is a very small number of services interested in quality certification, which could greatly help in maintaining their quality. Even with the Commission of Mammography to do this task, there is already a service which sought by its own means and by the competence of its board of directors to undertake a comprehensive audit including an evaluation of technicians and images interpreters.

Breast cancer continues to affect women. There is a great preoccupation with early breast cancer detection, particularly from the part of Sociedade Brasileira de Mastologia (Brazilian Society of Mastology) and CBR, but the Government takes a step back and recommends delayed mammography screening. Maybe, if the Government enforced the law to make the services undertake audits and forwarding the data to enable the Health Ministry to adopt appropriate measures, we could observe a considerable reduction in mistakes.

On the other hand, as regards women ... Depending on their social class, several diagnostic options are available (digital breast tomosynthesis, magnetic resonance imaging). Who has already made an audit to know the advantages/disadvantages of these more expensive imaging methods to save women? Women must be well informed and guided, even to know where they should go to have their breasts examined - a reliable service, not because someone said, but because she has actual data proving the efficiency of such service.

\section{REFERENCE}

1. Badan GM, Roveda Júnior D, Ferreira CAP, et al. Auditoria interna completa do serviço de mamografia em uma instituição de referência em imaginologia mamária. Radiol Bras. 2014;47:74-8. 